\title{
The Rewards of Qualitative Assessment Appropriate to Study Abroad
}

\section{Lilli Engle}

American University Center of Provence

With the interconnectedness of the peoples and nations of our world every year more patently apparent, the international education community has responded with heightened urgency to the challenge of integrating the discovery and understanding of other countries, cultures, and realities into the university curriculum. Even as all involved still search for the best ways to go about achieving these extended educational goals, numbers boom. Open Doors 2012 reports that the number of Americans studying abroad reached 273,996 in the 2010/11 academic year, with over three times as many American students studying abroad than there were just 20 years ago. ${ }^{1}$ Fairs, conferences, and publications contribute energetically to advance this mission. And study abroad opportunities multiply.

But such growth has ushered in another, questionable, trend. With the rapid increase in student numbers has come the influence of the market place. We speak more openly now of the "industry" of study abroad and, in good consumer fashion, program success and longevity rely more heavily on student "word-of-mouth" support than on considered professional recommendations.

The question imposes itself: Do consumer and educational goals, values, and priorities make good bed-fellows, especially as concerns study abroad? Current practice reveals that the marriage is problematic, if not antagonistic.

On the one hand, the profession embraces lofty intercultural learning goals, advocating the need to take students out of the comfortable, familiar confines of home university environments in order to allow them to experience and understand ways of being and doing sometimes disturbingly different from their own. On the other, having based their reputations in large part on extensive student/client services, many institutions of higher learning put implicit (and sometimes explicit) pressure upon their program providers to perpetuate a recognizable version of home university expectations and comforts for their students abroad.

The reluctance to challenge students with difference, at the risk of making them unhappy, has generated a culture of incompatible goals and mixed messages - an ideological tug of war that leads, all too often, to a significant mobilization of time, energy, money, and talent for mitigated learning 
outcomes that are rarely measured, documented, or otherwise addressed.

In an attempt to see beyond the numbers and percentages of students studying abroad each year, the profession has progressively engaged in a range of outcomes assessment initiatives. Organized jointly by IIE (Institute of International Education) and NAFSA, covering 120 universities (accounting for nearly $50 \%$ of U.S. study abroad participants), a 2000 survey of such assessment practices revealed home institutions preoccupied more by a "student comfort" model than by concerns about learning outcomes abroad. Ninetyfive per cent of these assessments aimed to document student satisfaction with far fewer attempting to document other, more educational, parameters. A few examples:

- Only 40\% measured gains in language proficiency

- Fewer than a third assessed academic achievement or personal development

- Fewer than $10 \%$ measured career-related outcomes

- Just $15 \%$ assessed gains in intercultural proficiency. ${ }^{2}$

The conclusion of this study was simply stated and unmitigated: "From this sampling it is clear that the majority of the profession is far from engaging in serious outcomes research beyond the question of student satisfaction.”

Twelve years later, quantitative assessment initiatives attempt to measure aspects of student learning abroad often with sobering results. A major recent study documents the minimal intercultural sensitivity development resulting from current approaches to program design and implementation. ${ }^{3}$ There are many reasons why the American student encounter with cultural difference abroad rarely provokes the transformational learning so ardently espoused. But a cross-section of qualitative assessment questionnaires currently in use suggests at least one angle of investigation.

For the purpose of this article over 50 end-of-program evaluation forms from universities known for their investment in international education were examined. The forms were provided either by study abroad offices or freely accessed via the internet. The questions put to students in these qualitative assessment questionnaires paint a picture of a profession all too ethnocentric in its approach to international education. Many of the questions were to be answered on a sliding Likert scale. The "customer satisfaction" slant was pervasive, expressing itself through such questions as:

- How would you evaluate your study abroad experience?

- How would you rate the foreign language instruction in this

program?

- How do you rate the program?

- Any suggestions for improvement? 
- Did your stay live up to your expectations?

- What was the least satisfying part?

- I accomplished the academic goals I had set for my study abroad experience.

- I am satisfied with my study abroad experience.

- The program offered an adequate number of activities and excursions.

- Overall, how worthwhile was your study abroad experience?

- What was your perception of your on site director (program assistant, resident director) overseas?

- Please comment on your access to computers, the internet, and email this year.

- What was the average waiting time to get into the computer lab?

Of the 50 qualitative assessment questionnaires reviewed, some targeted individual programs; others, especially those provided on-line, encompassed all the study abroad programs sponsored by the home institution. Programspecific questionnaires generally allowed for more personalized student comments, but too often they also fell into essentially the same pattern, leading ultimately to the same question: "Would you recommend this program to other students? Why or why not?"

These sorts of questions are so commonly employed as to sound perfectly "normal" and acceptable. Yet with the pressure to keep students "happy" comes the temptation to back away from the "no pain, no gain" truth that lies at the heart of the process of adaptation and personal growth.

Aware of the pitfalls involved when communicating across cultures, anthropologist Edward T. Hall discusses the goals and challenges that international educators and their students all face:

Our purpose should be to facilitate human interaction ... and to loosen the unconscious grip of culture ... so that human beings can face the future in a quite new and more adaptive way. In setting these objectives, I do not mean to give the impression that our task will be easy. On the contrary, it is probably more difficult than anything the human species has thus far attempted. Paradoxically, the individual steps to cultural and personal comprehension are not inevitably difficult. It is the changing of behavior, and the integration of new patterns that lead to greater self-knowledge, that tax us most. ${ }^{4}$

In theory, the field of study abroad aspires towards providing a change in learning environment and subsequent transformational learning. In reality, reflecting a strong bias towards an ultimate goal of consumer contentment, satisfaction-based end-of-program questionnaires refer students back to their 
pre-departure expectations. More often than not, students are called upon to examine the quality of their term abroad through the lens of accepted American standards of teaching style, internet access, staff availability, or housing comfort. This form of questioning hardly acknowledges or supports the often difficult cultural adaptation to things "different" and its subtle, profound rewards.

In word and deed, then, the profession oscillates in its priorities and promises between:

- the model of static (established, familiar, comfortable) student/ client-centered satisfaction largely based on expectations determined by home university standards, and

- the model of dynamic (foreign, different, disturbing) opportunities for personal development and new ways of learning.

While student interest and satisfaction will invariably continue to impact a program's success, the challenge we face today is to bring more appropriate criteria to the consideration of "satisfaction"; criteria more in keeping with the ideals of international education, which acknowledge the rigors, risks, and rewards of a genuinely different (i.e., intercultural) experience.

A worthy goal may be to align the notion of "satisfaction" with these higher educational ideals; to do so entails a certain clarity of mission and purpose for only if we ourselves truly believe that study abroad is much more than travel and a simple change in geographical location, and that the intention of international education is new knowledge, broader perspective, self-discovery, and respect for things lived and done differently than at home, only then will students be guided to perceive "value" not on the basis of familiar consumer comforts but on the basis of a discernibly different educational challenge and its unique rewards.

If educators hope to achieve a fundamental shift in student perspective, all program elements from the introductory website description to program design and implementation on both educational and administrative levels must align in their attempt to convey the value and importance of the declared intercultural goals. Such continuity in word and deed can inspire in students a secure sense of guidance and purpose and, like good parenting, both focus and liberate the potential for learning and personal growth.

Strange as it may seem, in looking for a reliable indicator of a program's mission and priorities, the end-of-program qualitative assessment questionnaire is an excellent place to begin. The choice and formulation of questions put to students reveal much about the essential purpose and internal coherence of programs, or lack thereof. It follows that, through a kind of reverse engineering, the considered process of creating or revising a program's 
evaluative questionnaire can actually help bring clarity of mission and coherent focus to the design and implementation of the program itself.

An artfully designed qualitative assessment questionnaire supports home campus requirements of student satisfaction-based accountability, while validating the importance of the unsettling encounter with difference and the resulting shifts of perspective fostered by international education at its best.

To engage in the examination of conflicting values inherent in our evaluative questioning is in a way to embark on a kind of personal journey, a bringing to awareness and a reconciling of divided loyalties. Aiming at that reconciliation, what follows outlines the process of placing a more appropriate set of values at the heart of qualitative assessment questionnaires.

\section{Assessing "Quality" in a Cross-Cultural Context}

The tendency in the U.S. is to attribute particular weight and importance to quantifiable data. Quoting the sociologist F. Kluckhohn with regard to aspects of American life, Bennett and Stewart remind us that "its most distinctive feature is a demand for the kind of activity which results in accomplishments that are measurable by standards conceived to be external to the acting individual." 5

Unlike quantitative data, qualitative evaluations solicit judgment or conclusions about the value or merit of whatever performance, places, or events are targeted for review. For those who resist the notion that all aspects of complex human experience can be quantifiably measured, qualitative questioning brings welcome context to the quantifiable data by gathering valuable subjective student feedback.

Qualitative feedback is founded of course on necessarily subjective opinion. One may rate the "quality" of a car, for example, in terms of luxury styling while another may associate quality with ecological efficiency. Luxury styling vs. ecological efficiency: the choice depends on the values at the heart of the judgment.

In study abroad, qualitative assessment brings focus to the students' own appreciation of their lived experience abroad. But in a cross-cultural context, opinions and value judgments are hazardous in that they inherently invite comparison between the host culture and familiar home-based standards. Qualitative assessment leaves little room for the appreciation of cultural difference unless the questions themselves are appropriately framed to encompass a broader, more ethnorelative perspective.

At home, cultural norms or expectations pre-establish the criteria upon which judgments of quality or merit can be reached or measured. Such judgments have shared cultural meaning and are thus readily understood. 
However, as soon as cultural boundaries are crossed, criteria of quality naturally change, and the notion of "quality" itself in any absolute terms becomes increasingly relative and elusive.

Outside the ethnocentric sphere of accepted cultural norms, what value or meaning do qualitative terms such as the following carry?

- The pre-departure information I received from the program was adequate.

- $\quad$ My meeting with the Office of Study Abroad advisor was helpful.

- The instructors were effective.

- The program was intellectually challenging.

- I am satisfied with my study abroad experience.

Only shared cultural experience allows us to "read into" and bring meaning to such words which inadvertently bear ethnocentric reference unless otherwise framed. Thus the question arises: If the primary aims of international education are to expose students to "difference," to foster crosscultural understanding, and to cultivate in students an essential empathic shift in perspective, are judgments of "quality" based on home culture standards legitimate at all?

Case in point: An American student, used to a detailed syllabus, assigned readings, classroom debates, and friendly, accessible professors, goes to study in one of the many other parts of the world where a quality university education does not integrate a syllabus or specifically assigned readings, where students learn independently, and where professors maintain a hierarchical distance, lecturing to large groups of receptive students who take copious, synthetic notes.

This cross-cultural encounter frequently results in the negative judgment of the study abroad student who views host classmates as "passive," host professors as "distant" and "disorganized," and course material as largely inaccessible. As a result, overseas host institutions fall under pressure to adapt to American learning styles and to home university administrative expectations.

Instead of validating a stretch in perspective, qualitative questionnaires often reflect the unquestioned merit of the student-centered learning style so typical of the American classroom, and evaluative questions such as the following, with Likert scale response choices, openly encourage ethnocentric reference:

- The course objectives and expectations were clearly identified before the course began.

- Rate the professor

- Quality of instruction

- Attitude towards students 
- Accessible to students

- Please rate each course according to the following criteria:

- Quality of the course

- Appropriateness of exams/assignments

- Level of difficulty as compared to home university course

- The program was well-organized

To avoid the pitfalls of ethnocentric judgment, questions may take another form, in part, by asking for more specific indications of how the students lived and benefitted from the experience that the program intentionally structured for them. To this purpose, an evaluation form supportive of transformative learning and personal growth needs to be informed by clearly established program goals which then become the central preoccupation and focus of each question. Inherently acknowledging the value of difference, such questions expand the students' frame of reference rather than close it by implicit comparison to the already known. For example, consider several questions crafted to acknowledge the challenge of direct enrolment. Likert scale response choices can be applied where necessary. For example:

- The host classroom environment differed considerably from that of my home university.

- Classes and assignments were less structured and required more independent learning.

- I found it very difficult to adapt to (check all that apply):

Language of instruction

Class size

Fewer structured assignments

Fewer assigned readings

Less classroom debate

Relative inaccessibility of the professor

- I relied on the following to help me adjust to a new learning style (check all that apply)

My host national classmates (shared notes, conversations, independent study groups)

Pooled resources with my American classmates

Outside readings in the subject matter

Advice from the professor and/or on-site resident director

Tutorial assistance

- The host culture learning environment (check all that apply)

Pushed me to find new learning resources in myself

Made me more aware of the way learning is organized at 
home

Discouraged me due to lack of direction

Liberated me to take more responsibility for my learning process

Prepared me to better face future challenges

- $\quad$ Additional personal comments (A non-directive invitation to voice praise or concerns)

In short, by formulating questions which acknowledge the difficulty in adapting to cultural difference, and placing emphasis on what the program hoped to achieve, we glean a sense of the student's lived experience while reenforcing intercultural respect and understanding. Questions appropriate to the study abroad context guide students away from the indulgence of ethnocentric judgment and toward the awareness of their own accomplishment in the face of cultural difference.

Finally, the very act of responding to thought-provoking questions can contribute to the important process of fixing memory and the lasting formulation of personal history. Asking the right questions can allow students a precious opportunity to get in touch with how they experienced and, thus, how they will remember their time abroad.

\section{Aligning Actions and Ideals}

\section{Crafting the Mission Statement}

As convenient as it would be, it is impossible to formulate a sole endof-program evaluation form suitable to a variety of program types. One size does not fit all. Clearly defined program goals reside at the heart of a coherent qualitative assessment effort, and learning goals vary as widely as do programs within the field. General, multi-program forms only encourage reliance on consumer-oriented, student satisfaction-based questioning for lack of any other stated or implied common objectives.

In its Standards of Good Practice for Education Abroad (2011), the Forum on Education Abroad assigns paramount importance to the guiding mission statement:

1. Mission: The organization, with respect to education abroad, has a formally-adopted mission statement for its overall operations and for its individual programs, that is known to and accepted by its faculty and staff.

a. Mission and Commitment: The organization has mission statements appropriate for each program. 
i. What is the organization's mission statement in regards to its education abroad programs?

ii. What are the specific objectives for each program?

iii. How does the organization define expected outcomes?

Ideally, meaningful assessment completes a circle. A finely established mission statement as point of departure will guide and inform all that follows and logically find its affirmation in the resulting outcomes. The full cycle appears graphically in Figure 1.

Figure 1. Meaningful Assessment Completes a Circle
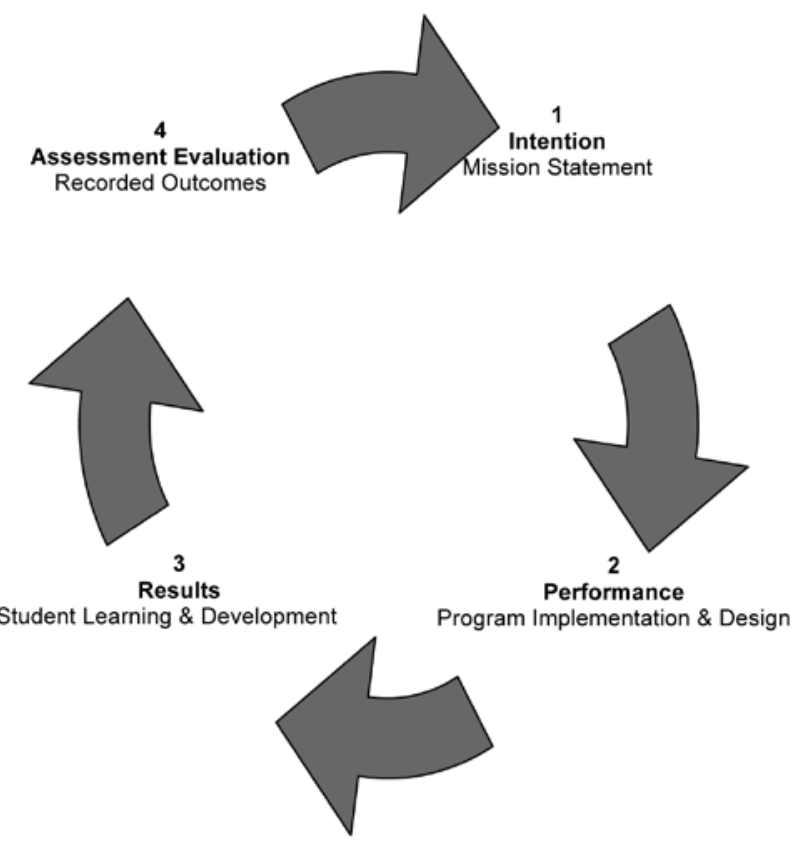

Inescapably, evaluative questions presented to study abroad students both reflect and support program priorities, whether oriented toward student satisfaction or transformative learning. If the assessment process aligns with the program's declared objectives, as inspired by a clear mission statement, program goals will find their echoed voice in the end-of-program questionnaire. Unfortunately, this does not always occur. The easy route toward student contentment offers many opportunities to go astray; all the more reason, in keeping with Forum standards, that a program's mission and related goals be 
adopted and supported collectively by all faculty and staff.

Writing a mission statement is a powerful exercise in putting intention into words, a process our counterparts in the world of business have mastered. Longer on words but never short on ideals, university mission statements related to study abroad generally commit to "internationalize the campus," as the following key-line excerpts express by way of clearly stated goals:

- become a leader in global education among private liberal arts colleges

- provide and facilitate quality international educational opportunities

- promote the academic, personal, professional, and intercultural development of students before, during, and after their study abroad experiences

- respond effectively to student needs, contribute to campus internationalization, and foster cultural understanding and selfawareness among the student body.

- enhance the internationalization of the undergraduate experience

- develop future leaders in an increasingly interdependent global society

\section{Designing Programs with Clear Intention}

University mission statements commit to what will be done, in more or less detail. As Table 1.1 illustrates, the stated Intention or Mission Statement informs the Performance or Implementation phase, and study abroad offices and individual study abroad programs mobilize to put into action the how of the endeavor. Their individualized mission statements would logically go into the detail of more specific intervention objectives and strategies.

However, today, regardless of the Standards of Good Practice, program mission statements are rare and statements of mission or purpose must most often be inferred from indications of Program Type. With its proliferation of opportunities, study abroad has become a generic term that can encompass experiences that range from a study tour of a few weeks to a semester or yearlong service learning commitment. In search of a program that meets their desired goals, both students and study abroad administrators must determine an appropriate choice largely from the combination and nature of the program components: duration of study, prior foreign language requirement, language of instruction, context of academic work, type of housing, provisions for integration activities, and orientation/on-site mentoring. ${ }^{7}$

The progression from Intention to Performance, from Mission Statement to Program Design and Implementation, invariably encounters pragmatic concerns and requires close vigilance if coherence of purpose is to be 
maintained. Imagine a study abroad office that realizes the importance of a pre-departure orientation session. The first question toward implementation becomes:

What ideally do we want a pre-departure orientation program to do?

- Answer students' logistic concerns

- Provide pertinent visa and travel information

- Prepare students psychologically for the cross-cultural challenge ahead, etc.

With clear purpose attributed to the orientation program, the subsequent evaluative questions write themselves and give transparent meaning to the terms "adequate" or "satisfactory," in addition to employing a format suitable to on-line data collection. Answers can be given on a sliding Likert scale:

- The pre-departure orientation session:

1. Answered my logistic concerns

2. Provided all necessary visa information

3. Prepared me for the process of adapting to a new learning environment

The deceptively simple process of breaking down goals into the action verbs of implementation keeps all actors in alignment, creating a synergy of intention and effort from which students can only benefit at home and abroad.

Once again, such concrete intention in turn makes the assessment process much clearer and simpler since the program maintains a clear view of what it hopes to achieve.

Program component: Integration Activities

Component goal(s): Offer opportunities for connectedness and sharing outside the student/learner framework.

\section{Sample Question:}

- The program's integration activities offered opportunities for connectedness and sharing outside the student/learner framework.

(Strongly agree / Somewhat agree / Neutral / Somewhat disagree / Strongly disagree)

Program component: Housing

Component goal(s): Offer a forum of communication, cross-cultural understanding, and personal bonding.

\section{Sample Question:}

- My housing offered an opportunity for friendship and interpersonal closeness and sharing.

(Strongly agree / Somewhat agree / Neutral / Somewhat disagree / Strongly disagree) 
Program component: Academic program /Course work

Component goal(s): Establish a link between the course content and the study abroad location.

\section{Sample Question:}

- The academic program established a close link between the course content and the study abroad location.

(Strongly agree / Somewhat agree / Neutral / Somewhat disagree / Strongly disagree)

Consciously applied, clarity of intention brings coherence to the entire study abroad endeavor. In contrast, the more intention and guiding purpose waver or falter or dissipate, the less energy comes to bear on the synergistic orchestration of student learning strategies.

\section{Including the Student Component}

In study abroad, the educational experience extends far beyond the confines of the classroom. Learning can take place everywhere; such is the promise and potential magic of the opportunity. Student motivation and level of preparedness factor heavily in the realization of this potential. Yet recent studies show that our current generation of students relies so heavily on guidance and structure that, without professional mentoring, they simply fail to seize the opportunities for encounters and discovery, and subsequent learning, which their new learning environment provides. ${ }^{8}$ For aptly labeled colonial students, ${ }^{9}$ the intervention of trained and skilled professionals is essential to the complex learning experience that is study abroad. The profession would be unwise to expand more quickly than the resource of such expert staffing allows.

That said, in order to put study abroad efforts and their subsequent outcomes in proper perspective, we must address a simple truth: no university or program can guarantee a study abroad experience. Certainly they can provide a planned and constructed learning environment. But the experience of that environment is part of a dynamic encounter, personal to the individual student. Experience is a personal creation. In learning outcomes, responsibilities are shared. No one can give a student an experience, and no assessment effort can be fair or complete without integrating the consideration of student responsibility into the learning process.

In this context, students may logically be called upon to assess qualitatively their own motivation, attitude, investment, academic performance, or ability to take risks - to assess, in essence, what they themselves brought to their experience. 
Program component: The student

Component goal(s): Actively engage in the learning experience inside and outside the classroom.

\section{Sample Question:}

- I invested in my study abroad learning experience in the following ways:

Spoke the host language at every occasion, even with my American classmates (Strongly agree / Somewhat agree / Neutral / Somewhat disagree / Strongly disagree / N/A)

Engaged intellectually in the course work

(Strongly agree / Somewhat agree / Neutral / Somewhat disagree / Strongly disagree / N/A)

Attended class regularly

(Strongly agree / Somewhat agree / Neutral / Somewhat disagree / Strongly disagree / N/A)

Did assigned readings and projects

(Strongly agree / Somewhat agree / Neutral / Somewhat disagree / Strongly disagree / N/A)

Asked insightful questions

(Strongly agree / Somewhat agree / Neutral / Somewhat disagree / Strongly disagree / N/A)

Sought out opportunities for independent exploration in the host culture (Strongly agree / Somewhat agree / Neutral / Somewhat disagree / Strongly disagree / N/A)

Put judgments aside in order to learn to appreciate host nationals (local professors, classmates, and/or host families) within their own cultural context (Strongly agree / Somewhat agree / Neutral / Somewhat disagree / Strongly disagree)

\section{Completing the Cycle of Learning}

In conclusion, the conception and implementation of the ideal qualitative end-of-program questionnaire provides an exercise in awareness of intention and a record of accountability both for the program and for the students.

\section{For the program}

Questionnaires that validate the uniqueness of learning abroad acknowledge that study abroad encompasses a wide range of program types, each with varying objectives, means, and challenges. The choice and formulation of the questions set the criteria for qualitative judgment based on the educational goals, in both academic and transformative learning, set out by the individual program (or Program Type) instead of relying on general criteria of home-based student/client satisfaction. 
The process of producing a thoughtfully conceived questionnaire allows program administrators at home and abroad to collaborate in order to:

Formulate, revise, or confirm a mission statement suitable to logistical resources;

Consider and articulate, component by component, what the program hopes to achieve;

Evaluate the suitable interconnectedness of program components in light of the learning objectives declared;

Validate the degree of adaptational challenge confronted by the studentlearner abroad;

Consider and determine optimum student preparedness and criteria for participant selection in keeping with program goals.

A complete handbook designed to guide this process is available as part of the on-line toolkit made available by the Forum on Education Abroad. ${ }^{10}$

\section{For the students}

In moving away from a generalized customer-satisfaction opinion poll, a thoughtful study abroad questionnaire enables students to:

Recognize and reflect upon the value in the deliberate educational challenge of their study abroad experience;

Place their personal, academic, and cross-cultural experience within the context of specifically stated program goals;

Reflect on their own ability or motivation to seize the opportunities provided;

Assume responsibility as creators of their own experience.

The end-of-term evaluation process allows program administrators to record and examine more precisely the effectiveness of their efforts completing the cycle of alignment and accountability. For the student a well-written form can serve to refine and enhance the learning process by framing a moment of articulate introspection, offering a structured opportunity to record in word and in memory a very personal experience of learning and growth.

More importantly, questions that acknowledge and bring value to the sometimes difficult encounter with difference allow students to see themselves as having undertaken the worthy challenge of positioning themselves, their behavior and views, within the extended context of other cultural realities. Is this not the path to becoming the much acclaimed "global citizen"?

Finally, by refusing to indulge ethnocentric criteria of student satisfaction 
in the evaluation of program performance and success, we shift our focus from uniquely home-based student/client expectations to the acknowledgement of precious differences in the overseas learning environment. Who's adapting to whom? With this implicit question more appropriately embedded in the questions we advance, students may be guided to find greater empowerment in the value of their personal and academic intercultural achievement than in client-based demands. Questions formulated in support of the challenging complexity of the learning experience abroad-of which evaluation is the invaluable epilogue-speak to a humbler, more respectful acceptance of the world's cultural diversity, which is, let's not forget, the fundamental resource of study abroad itself.

\section{Endnotes}

${ }^{1}$ Institute of International Education. (2012). Open Doors 2012 Fast Facts. Retrieved from: http://www.iie.org/Research-and-Publications/OpenDoors/Data/Fast-Facts (4 February 2013)

2 Sideli, K. (2001). SECUSSA/IIE Electronic Sampling Results, Survey \#2: Outcomes Assessment and Study Abroad Programs: Commentary on the Results of a SECUSSA/IIE Electronic Sampling. International Educator, 10, (2), 30. Retrieved from: www.secussa.nafsa.org/ samplingresults2.html (20 June 2006)

${ }^{3}$ Vande Berg, M., Paige, R. M. \& Connor-Linton, J. (2009). The Georgetown Consortium Project: Interventions for Student Learning Abroad. Frontiers: The Interdisciplinary Journal of Study Abroad, 18, Fall, $1-75$.

${ }^{4}$ Hall, E. T. (1983). The Dance of Life: The Other Dimension of Time. New York: Doubleday. pp 9-10.

${ }^{5}$ Stewart, E. \& Bennett, M. (1991). American Cultural Patterns: A CrossCultural Perspective. Yarmouth, ME: Intercultural Press, Inc., p 70.

${ }^{6}$ Standards of Good Practice for Education Abroad (2011). Carlisle, PA: The Forum on Education Abroad

${ }^{7}$ Engle, L. \& Engle J. (2003) Study Abroad Levels: Toward a Classification of Program Types. Frontiers: The Interdisciplinary Journal of Study Abroad, 9, Fall, 1-20.

${ }^{8}$ Vande Berg, M., Paige, R. M. \& Connor-Linton, J. (2009). The Georgetown Consortium Project: Interventions for Student Learning Abroad. Frontiers: The Interdisciplinary Journal of Study Abroad, 18, Fall, $1-75$.

${ }^{9}$ Ogden, A. (2007-2008) The View from the Veranda: Understanding 
Today's Colonial Student. Frontiers: The Interdisciplinary Journal of Study Abroad, 15, Fall/Winter, 35-55.

${ }^{10}$ Engle, L. \& Martin, P. (2009) Alignment \& accountability: The effective design and implementation of qualitative assessment for education abroad. Retrieved from http://forumea.org/standards-toolbox.cfm (4 February 2013) 